\title{
Common thermal and shrinkage cracking of ceiling slabs
}

\author{
Jacek Hulimka ${ }^{1, *}$, Szymon Dawczyński ${ }^{1}$, and Rafał Krzywoń ${ }^{1}$ \\ ${ }^{1}$ Silesian University of Technology, Dep. of Structural Engineering, Akademicka 5, Gliwice, Poland
}

\begin{abstract}
Early age cracks of concrete structures are usually associated with the phenomenon of shrinkage. Most often they appear after a few days of hardening of the concrete. The appearance of shrinkage cracks results from the constraint of the structure, including inhomogeneous volume changes of the concrete. Due to the variety of reasons that can cause early age cracks, it is often difficult to diagnose them properly, and especially to recognise them from the more serious damages caused by load capacity deficits. The paper presents a few cases of shrinkage cracks of ceilings, met by the authors in their professional work. The examples were selected to show different types of design and construction errors that contributed to the occurrence of excessive shrinkage cracking. These include maladjustment of concrete care for the weather conditions, local structural restraints that limit the freedom of deformation of the ceiling, the lack of expansion joints or too large breaks in concrete placing.
\end{abstract}

\section{Introduction}

Cracks are almost inevitable for everyone concrete structure. Most of them are not visible to the naked eye and are not considered as a danger for structure durability, serviceability or bearing capacity. Except for crack width, assessment of danger associated with the occurrence of cracks requires the identification of their causes. First cracks may appear before concrete hardening, from 10 minutes to 6 hours after placing [1]. These cracks are caused by mix settlement, construction (formwork) movements and excessive evaporation of water.

Restraints of concrete volume changes caused by the walls or stiff ribs may lead to the occurrence of early age slab cracking. It is generally known, that early age volume changes are related to a combination of shrinkage and thermal effects. The amount of concrete volume change and the degree of restraint can be categorized into three groups, related to material properties of concrete, structural issues and construction techniques.

The main cause of excessive shrinkage is the poorly selected composition of the concrete mixture. As it is widely known, the main factor decisive for the amount of shrinkage is water to cement ratio. Low w/c reduces the loss of water and thus volume change of concrete. The amount of water can be efficiently reduced by addition of superplasticizers. This action allows maintaining the required workability of concrete mix. Similarly, high aggregate to

\footnotetext{
* Corresponding author: jacek.hulimka@polsl.pl
} 
cement paste ratio usually reduces cracking. Especially the addition of low shrinkage and thermal expansion type of aggregate is beneficial in this case.

The second option to reduce early age cracking is to delay the set time. Addition of supplementary cementitious materials (e.g. fly ash, natural pozzolans) decrease the set time by reduction of hydration rate and thus limits the setting temperature rise and early strength development. Hydration can be also delayed by addition of retardants; however retarded mortar may have higher early shrinkage [2]. The harmful is too slow growth of strength. Usually, within the first 5 hours, modulus of elasticity growths faster than strength, what promotes early age cracking.

Shrinkage may be successively reduced by addition of shrinkage-reducing admixtures or use of shrinkage-compensating cement.

Structural solutions as a cause of early age cracking are generally underestimated by designers, especially in the case of ceilings. Structural factors are usually related to restraints caused by:

- $\quad$ stiff supporting walls or beams, especially in relation to the ceiling stiffness,

- $\quad$ support conditions, fixed-end (e.g. integral tie beam) creates boundary restraints and thus increases cracking,

- location of the ceiling area, usually interior spans are subjected to increased restraint, compared to end spans,

- lack or insufficient amount of expansion joints.

The group of incorrect structural solutions should also include problems resulting from the improper amount and arrangement of reinforcement [3]. Due to the restraints caused by stiff steel rebar, cracking may appear in case of too large bar diameter or bar spacing. Also, higher concrete cover initiates more cracks. It should be remembered that a higher concrete slump increases its settlement over rebar and thus promotes cracking. Early age cracks related to reinforcement usually have a similar pattern to the arrangement of reinforcing mesh.

The third group of causes of cracks are construction errors and probably the most underrated the influence of the external environment. To avoid early age cracks the concrete should be placed in the shortest possible time, if possible, the whole structure should be concreted at the same time. Mechanical vibration consolidates the concrete and thus closes plastic cracks. A similar effect on the surface gives the early concrete finish. Early age plastic cracking, which appeared 2-3 hours after placing the concrete, can be repaired by recompaction followed by a few hours of wetting [4]

Curing in humid conditions reduces the dry shrinkage and additionally enhances the durability and strength of concrete. Maintain of proper moisture content must be adapted to environmental conditions. Sun exposition and wind speed accelerate water evaporation [2]. A strong wind can cool concrete surface increasing the gradient of the temperature associated with the cement hydration and thus accelerating the cracking. Additionally, heating caused by the infrared solar radiation may provoke permanent thermal elongation, which, after hardening and cooling of concrete, causes long-term thermal stresses inside the structure [5]. It should be stated, that plastic shrinkage cracking may occur under ambient temperatures lower than $32^{\circ} \mathrm{C}$ and wind velocities below $48 \mathrm{~km} / \mathrm{h}$ [2].

High external temperature can also affect the properties of the concrete mix. The increase of initial mix temperature above $35^{\circ} \mathrm{C}$ reduces the compaction factor [6] and may enhance evaporation during transportation [7].

In the case of slabs, usually bottom surface is protected by formwork, thus most of the thermal and drying shrinkage-related cracks appear only on the upper surface. 
Patchwork cracking due to shrinkage and thermal effects usually appears within a few days of concrete hardening. However, in case of structures exposed to periodic winter cooling and summer heating (e.g. ceilings of multi-storey garages) shrinkage stress can be increased by temperature-related effects. In this case, cracking may occur within the first year of the summer-winter cycle [8].

\section{Examples of damage where the main cause was shrinkage}

The chapter describes several examples of shrinkage cracks met by the authors during their expert work. The examples were selected to show various causes of cracks and their impact on the visible crack layout.

\subsection{Concreting of the restrained ceiling under elevated temperature conditions}

The described structure is a reinforced concrete ceiling of the last storey in a two-storey building, free-standing, without basements, with office rooms and social facilities for employees. The overall dimensions of the building are respectively: length $27.34 \mathrm{~m}$, width $14.44 \mathrm{~m}$ and height $8.92 \mathrm{~m}$. Calculated on this basis, the usable floor area of the building is $643.82 \mathrm{~m}^{2}$ and the cubature of $3645 \mathrm{~m}^{3}$. The building was designed in a traditional, masonry construction - external walls were made of cellular concrete blocks and insulated with Styrofoam. The building's cover was designed in the form of a symmetrical flat roof plunged, with a small $\left(3^{\circ}\right)$ inclination of both roofs to the inside and the exit of rainwater through the inner channel outside the building.

In this object, the ceiling of the second storey was made as a monolithic reinforced concrete slab with a thickness of $0.14 \mathrm{~m}$. The ceiling was designed as cross-reinforced slabs with spans resulting from the functional distribution of the rooms located on the second floor and as a one-way reinforced slab over the communication hall (due to the small span). The designed concrete class was B30 (C25/30), and the BSt500S was the reinforcement steel grade (reinforcing bars with a diameter of $12 \mathrm{~mm}$ were used at a spacing of $200 \mathrm{~mm}$ ).

After disassembling the formwork of the second storey floor, a grid of irregular cracks appeared on its entire surface. The arrangement of cracks on the lower and upper surface of the ceiling did not depend on the span of individual slabs, nor on the location (in the span and support zones cracks were similar).

An example of the observed cracks of the lower surface of the floor is shown in Fig. 1a. On the upper surface of the slabs, it was more difficult to see the cracks, because they were covered with bound cement milk (Fig. 1b).
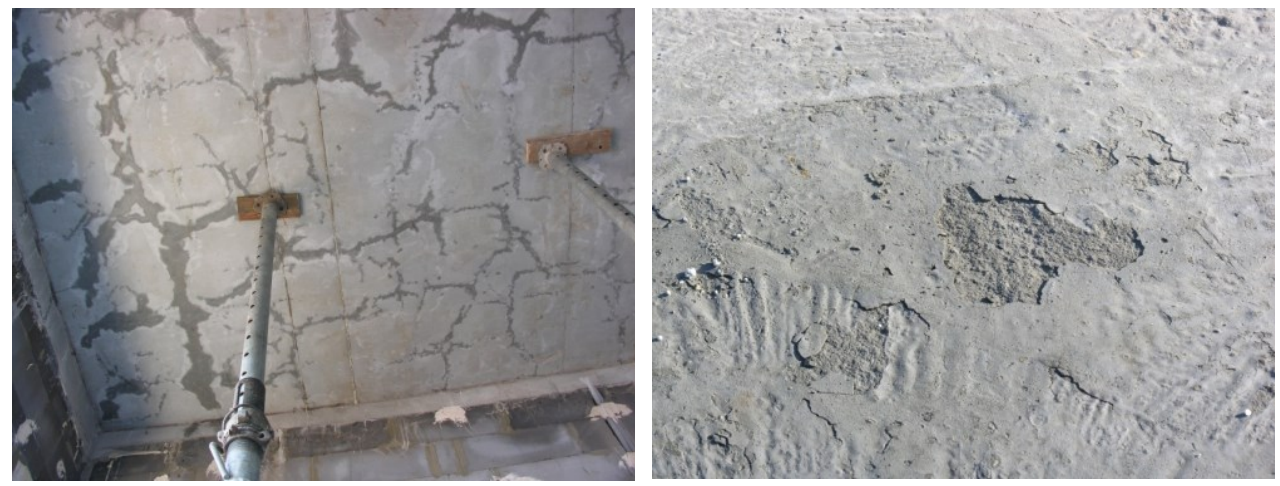

Fig. 1. An example of the observed cracks, a) on the bottom surface of the slab; b) on the upper surface of the slab (covered with cement milk). 
Due to the fact that the ceiling during construction was not sheltered from atmospheric precipitation, after the rain, it turned out that in the location of cracks on the lower surface of the slab, the water is filtered through the cracks (Fig. 2a). This fact, as well as the crosssectional appearance of the slab (Fig. 2b) at the place where the core sample was taken, clearly showed that the cracks were cross-cutting and went through the entire cross-section height.
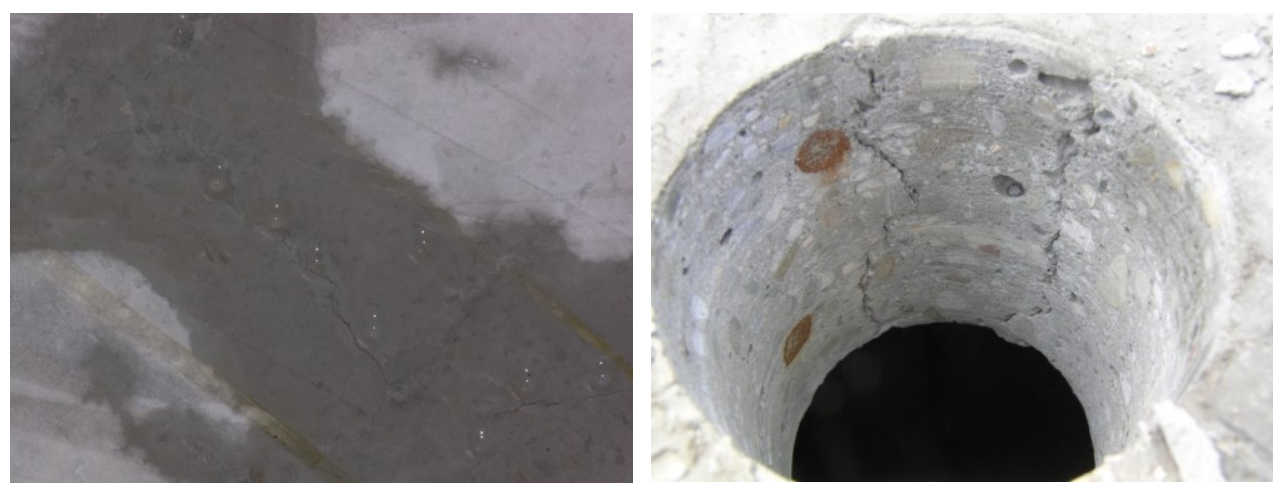

Fig. 2. a) The water filtered through the cracks (on the bottom surface of the slab); b) cracks in the slab cross-section (at the place where the core sample was taken).

The floor slab was made of concrete mix designed on the basis of CEM III/A 32.5N-LH-HSR/NA blast furnace cement, strength class 32.5, with normal early and low hydration heat resistance. As a supplement to the mix, the plasticizer Sika Plastiment BV $1 \mathrm{M}$ was used in the amount of $0.55 \%$ by weight of the cement content, i.e. in the range recommended by the manufacturer, $0.2 \div 0.8 \%$ [9]. It can, therefore, be concluded that the concrete mix has been adapted, as far as technically possible, to summer conditions.

In order to verify the quality of the mixture, a comparative analysis of the theoretical speed of concrete strength increase with the results of the samples taken by the concrete producer was carried out. Based on the catalogue sheet of CEM III/A $32.5 \mathrm{~N}$ cement produced by Górażdże Cement [10], it can be assumed that the strength of concrete containing $350 \mathrm{~kg}$ of cement in 1 cubic meter of the mix, with a w/c ratio of about 0.5 , after 9 days of maturation it should amount to approximately $31 \mathrm{MPa}$.

In addition, the speed of strength increase was limited by the addition of fly ash. With an ash content of $21 \%$ of the cement mass, the expected reduction in strength could reach about $25 \%$ [11]. Theoretically, considering the effect of ashes, on the 9th day after concreting, the concrete used should reach about $23 \mathrm{MPa}$. This value is approximately equal to the strength determined from the tests of the samples taken during concreting. In this way, the concrete producer's liability was largely excluded in terms of the incompatibility of its properties in relation to the declared parameters as well as the quality of the cement used.

From the documentation provided, it appeared that the ceiling slabs were concreted on July 9, 2011. The air temperature on that day reached $29^{\circ} \mathrm{C}$ [12] and was additionally accompanied by strong sunlight. The heating of concrete in such conditions could exceed $60^{\circ} \mathrm{C}$. Three days after concreting, around July 13, the weather collapsed; maximum daily temperature has dropped to $20^{\circ} \mathrm{C}$, and minimum night even below $10^{\circ} \mathrm{C}$. The average temperature drops a few days after concreting reached a dozen or so degrees.

Additionally, the increase in the temperature of the mixture stimulated the binding process itself. For cement with a hydration temperature of approximately $270 \mathrm{~J} / \mathrm{g}$, during the first three days of adiabatic curing, it is possible to increase the concrete temperature even at $20^{\circ} \mathrm{C}$ [11]. In the real situation, the growth itself is lower, because the heat is received by the environment, however, in conditions of strong insolation and high temperatures, the 
possibility of giving up the heat to the environment was limited. It can, therefore, be assumed with high probability that in the initial period the average temperature of fresh concrete reached even about $60^{\circ} \mathrm{C}$, then during the cooling period, in the second half of July, it dropped sharply to around $15^{\circ} \mathrm{C}$. Considering the average concrete deformation coefficient equal to $1 \mathrm{E}-5$, due to the relatively fast cooling, the relative deformation of the floor slab (short-cut) could be $0.45 \mathrm{~mm} / \mathrm{m}$.

The changes in volume accompanying the drying of the maturating concrete mix result in the occurrence of a shrinkage effect. This phenomenon is particularly dangerous at high temperatures that stimulate the rate of water loss and hydration of cement. It is believed [11] that cracks from plastic shrinkage can occur when the rate of evaporation exceeds the rate at which the filtered water rises to the surface. This means that not only the lack of care but also the break in its management may be dangerous. Evaporation increases with large differences between concrete and ambient temperature, low relative humidity and strong wind [13]. An important care treatment is in such conditions covering the concrete from the sun, which the contractor gave up. As a consequence of these neglects, an early shrinkage in concrete with a cement content of about $350 \mathrm{~kg}$ per cubic meter could reach as much as $1.7 \mathrm{~mm} / \mathrm{m}$ [11].

As it was shown, the total deformation of the concrete due to shrinkage and temperature change was likely to reach $2.0 \mathrm{~mm} / \mathrm{m}$. At maturation at normal, stabilized temperatures, strains due to deformation would be reduced by creep, however, in the present situation, as a consequence of heat, the creep effect was revealed to a very limited extent. The limitation of the possibility of free deformation of the floor slab caused by the rigid arrangement of the supporting walls as well as the bar reinforcement has led to described damages.

The cracking of the slab appeared in similar intensity on the entire surface of the ceiling. The spans and the arrangement of the walls and supporting posts did not have a visible impact on the concentration of cracks in places characteristic of the occurrence of maximum bending moments. Cracks permeated the ceiling over the whole thickness, without showing the characteristic for bending division into the cracked tensile zone, and the uncracked compression zone. This unambiguously excludes, as the cause of the cracks, the premature removal of formwork of the ceiling, before the concrete achieves the strength necessary to take over the dead load by its own.

According to the authors, the observed cracking of the ceiling was created only as a result of the accumulation of shrinkage influences and thermal deformations. This is evidenced, above all, by the regularity of the cracks' grid along the entire surface of the ceiling and their cross-nature, but also the lack of correlation between the dimensions of the spans and the placement of the supports, and the concentration of cracks.

\subsection{Restraint caused by the wall}

The case concerns a three-level car park with the dimensions of $92.5 \times 82.9 \mathrm{~m}$. The ceiling is divided by the expansion joints into nine approximately square segments. The regular arrangement disturbs the entry ramp along one of the roof edges. The structure of the car park can be classified as a flat slab with rectangular column heads in support zones. The ceiling slab has a thickness of $20 \mathrm{~cm}$. In the area of heads thickness increases to $45 \mathrm{~cm}$. The concrete slab was reinforced with top and bottom bars arranged in an orthogonal way. The upper surface was finished with a PMMA type flooring system.

After the winter period cracking appeared on the upper surface of the slab, mostly irregular, mainly in the span zones. Pattern and location zone clearly indicated the shrinkage increased by the winter temperature shortening as the cause of damages. However, some of the cracks along the entry ramp had a regular layout perpendicular to the edge of the ramp. Their spacing corresponding to the spacing of reinforcement in one of the directions. 
The shape of the ceiling segment next to the ramp is rectangular, additionally, the opening of the entry ramp is surrounded by a short masonry wall, which generates a constraint of free shrinkage and thermal deformation. The observed cracks appeared as a result of tensile forces, initiated by the concentration of stresses from the drying and plastic shrinkage around the upper reinforcing bars. Additionally, a clearly unidirectional lack of freedom of deformation along the wall caused a one-way distribution of cracks.

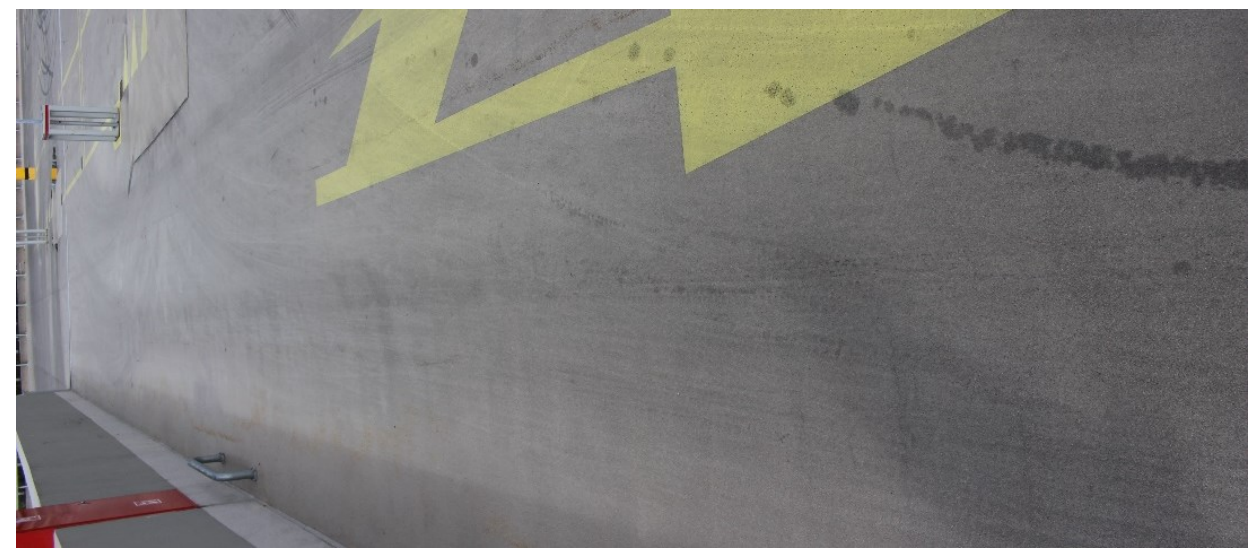

Fig. 3. The ceiling of the multi-storey car park, part of the wall surrounding the entry ramp and parallel crack pattern on the upper surface.

\subsection{Staged concreting}

Described ceilings are located in the underground level of a newly erected hotel. They were designed and made in a scheme of a flat slab. Ceilings in levels -2 and -1 are based on reinforced concrete columns and walls. The ceiling areas were made with an incrementally variable thickness, $22 \mathrm{~cm}$ in middle strips and $30 \mathrm{~cm}$ in a column strips in both directions. The ceilings were concreted in stages, with about a week break (level -2 in 5 stages, level -1 in 4 stages). The work was carried out in July and August.

Within a short time after the ceilings were made, cracks appeared in some of the ceiling areas. The layout of cracks in individual fields was accidental. Almost all cracks crossed the entire thickness of the ceiling and had a nearly equal opening.

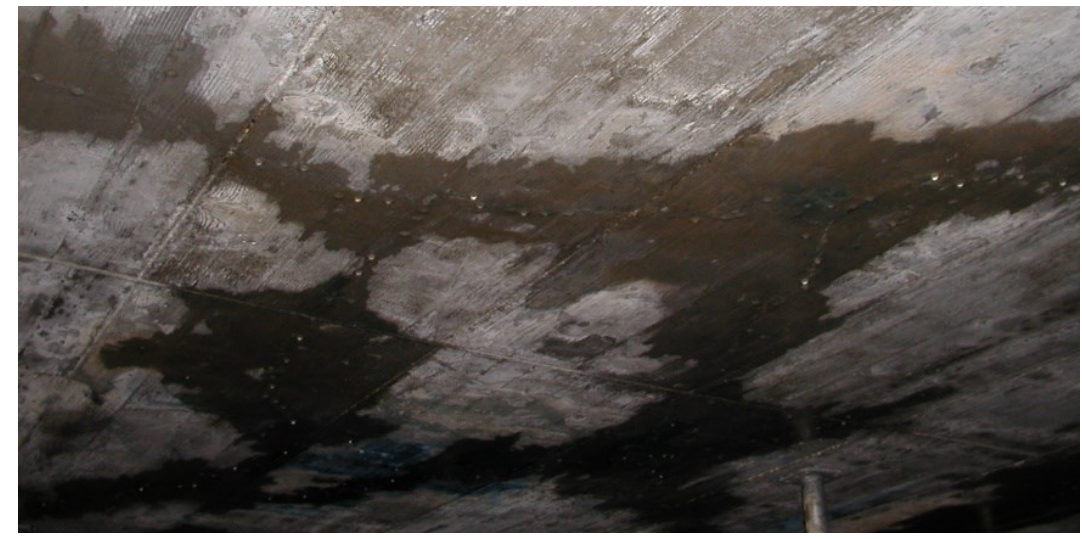

Fig. 4. Irregular cracks on the bottom surface of the ceiling. 
An irregular crack pattern indicated shrinkage as the cause of damage. The majority of shrinkage deformations occurred during the first 3-7 days after laying the concrete mixture. Free shrinkage deformations led to a shortening of the element without additional stress. The poured part of the slab had a free deformation limited only by columns. In the described case, the previously concreted and partially hardened segments of the ceiling created the constraint of shrinkage deformations of the newly-concreted segments, which caused the tensile stresses. In the first stage of concrete setting, when these stresses were the highest (rapid increase of shrinkage) and the tensile strength of concrete was negligible, the described situation provoked the formation of observed cracks.

\subsection{Lack of expansion joints}

The described case refers to the garage floor slab with a relatively large area $(45 \times 65 \mathrm{~m})$, made without expansion joints. The ceiling was supported on rigid reinforced concrete columns and circumferentially, on a very rigid reinforced concrete retaining wall. The described static scheme created almost complete restraint of the slab, which caused very high tensile stresses from shrinkage and, as an effect, the appearance of observed cracks (Fig. 5). An additional disadvantageous factor, in this case, was the concreting of the slab in the summer season, when the high temperature accelerated the curing of concrete and, as a result, the increase of shrinkage rate.

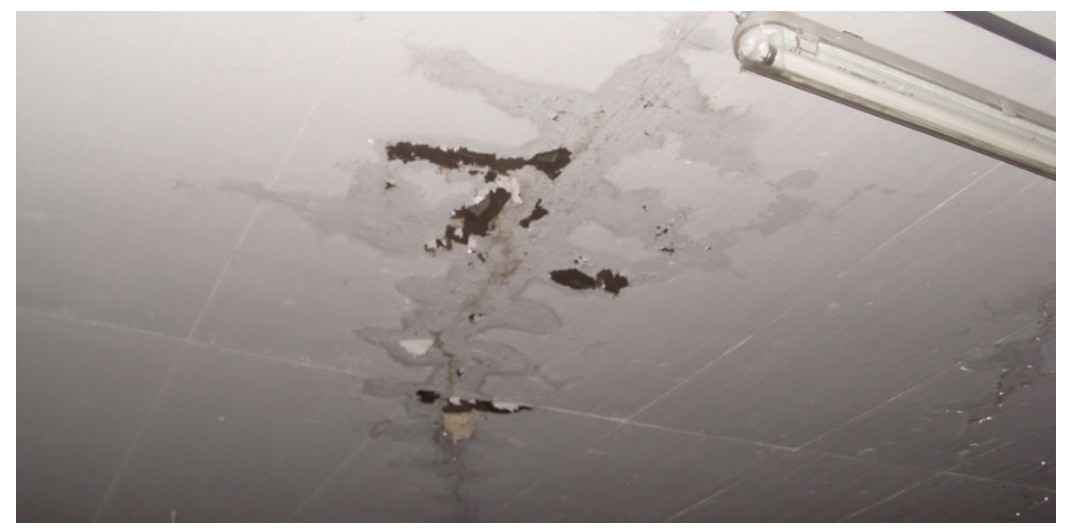

Fig. 5. The cracked and wetted bottom surface of the ceiling.

\subsection{Cracks initiated by an excessive drop of workability}

The described reinforced concrete slab is part of a newly erected industrial object. The structure of the building consists of two-storey double-span lateral frames, fixed in monolithic foundations and fastened in floor levels by longitudinal beams. The ceiling slab is $15 \mathrm{~cm}$ thick and made of $\mathrm{C} 30 / 37$ concrete.

The ceiling was made during the summer, the concrete was poured in mid-August. The external temperature in this period reached $+30^{\circ} \mathrm{C}$.

In a short time after the concreting of the structure of the ceiling, the appearance of a grid of cracks was observed on both surfaces. On the upper surface, the cracks formed a mesh that maps the layout of reinforcing bars (Fig. 6b). Some of the cracks have a clearly larger opening, exceeding $0.5 \mathrm{~mm}$. Cracks on the lower surface of the floor were similar, but they had less intensity. Part of the mentioned cracks cut the entire ceiling thickness, which was clearly visible after rainfall when the water migrated throughout the thickness of the slab. 


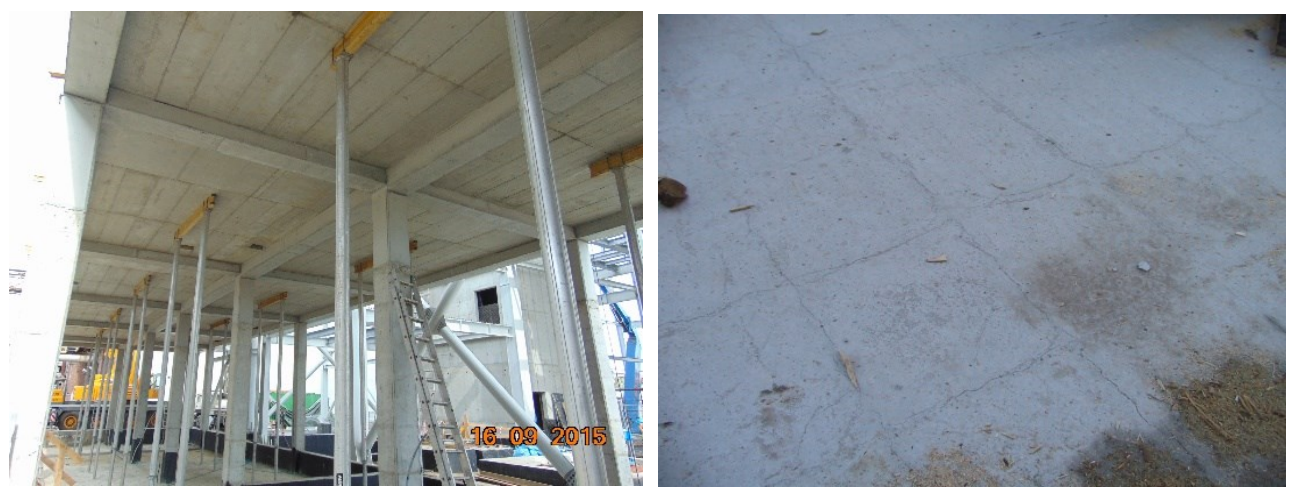

Fig. 6. Industrial ceiling, a) view of the structure; b) crack layout on the upper surface.

The cross-section of the columns in relation to their height is relatively small (Fig. 6a), the ceiling beams were concreted together with the slab, so the construction does not constitute a significant restraint for the deformability of the slab. The layout of the crack reflecting the reinforcement clearly indicates the improper concrete slump as the primary reason of cracking.

The concrete mixture was based on CEM II cement with the addition of fly ash. To improve workability, a superplasticizer for elevated temperatures was added to the mix. Observed cracking shows, that its ability to delay curing in the present case proved to be insufficient. Probably, in this case, it would be better to use a typical retarder. Factors that contributed to the further development of cracks were the relatively small ceiling thickness and errors in the wetting of concrete in the first period of curing. Due to the small thickness, the slab cooled too quickly during the night. On the first day of concrete curing, wetting was stopped due to short afternoon rain. Then, it was continued the next day, after a nearly 16-hour break.

\section{Conclusions}

The paper presents several examples of ceiling structures in which the excessive shrinkage cracking occurred. In none of the presented cases, the cracking did not threaten the loadbearing capacity of the whole structure, but it was intensive enough to disturb the users. Some cracks intersected the entire thickness of the ceiling, which resulted in the leaking of rainwater. Such a situation in a long term could directly lead to the corrosion of the steel reinforcement.

The appearance of shrinkage cracks can be caused not only by improper care but also by design errors regarding the concrete mix, structural scheme, construction technique and sequence. However, the cases described in this paper show that errors in the design of the mixture are rare nowadays. There is also visible a tendency to design restrained ceilings, without or with an insufficient number of expansion joints. In combination with the influence of temperature related effects, this leads to the formation of cracks, which are primarily caused by shrinkage deformations. Such cracks may appear even several months after the construction of the ceiling.

According to the authors, it is impossible to make reliable calculations regarding the appearance and the opening of cracks, because such calculations are subject to a number of assumptions, including the increase and distribution of shrinkage deformations, temperature changes in curing concrete and the increase of its tensile strength (all in variable support conditions, friction with formwork, changes in ambient temperature and humidity, method and intensity of care, variable weather conditions and a number of other unknowns). Adding 
to this the imprecise theoretical model of calculating the crack distribution and width, the result will be poorly related to the real behaviour of the structure.

The paper was prepared as a part of the implementation of the BK-237/RB-6/2018 project at the Department of Structural Engineering of Silesian University of Technology, Gliwice, Poland. Authors wish to acknowledge for the received financing from the University.

\section{References}

1. B. Klemczak, A. Knoppik-Wróbel, Arch. Civ. Eng. Environ., 2, pp. 35-48 (2011)

2. R. Shalon, Materiaux et Constructions, 11(62), 127 (1978)

3. M. Knauff, B. Grzeszykowski, A. Golubińska, Przykłady obliczania konstrukcji żelbetowych Zeszyt 3 (PWN, Warszawa, 2017) [in Polish]

4. J. Van Dijk, V.R. Boaroman, (Proceedings of the International RILEM Symposium on Concrete and Reinforced Concrete in Hot Countries, Haifa, 1, 225, 1971)

5. S. Asamoto, A. Ohtsuka, Y. Kuwahara, C. Miura, Cem. Concr. Res., 41, pp. 590-601 (2011)

6. F. M. Orb, (Proceedings of the International RILEM Symposium on Concrete and Reinforced Concrete in Hot Countries, 1, 112, 1971)

7. R. L'Hermite, (Proceedings of the International RILEM Symposium on Concrete and Reinforced Concrete in Hot Countries, 1, 1971)

8. Document: CIP-42-Thermal Cracking of Concrete (National Ready Mixed Concrete Association, 2009)

9. Document: Admixture for concrete reducing the amount of water Plastiment ${ }^{\circledR}$ BV $1 \mathrm{M}$ (former name Addiment BV 3 M), Technical Data Sheet, www.sika.pl

10. Document:Górażdże Cement, Blast furnace cement PN-B 19707 CEM III/A $32.5 \mathrm{~N}-\mathrm{HSR} / \mathrm{LH} / \mathrm{NA}$, www.heidelbergcement.com

11. A.M. Neville, Properties of concrete (Edition IV, Polish Cement Publishing House, Kraków, 2000) [in Polish]

12. Online: www.weatheronline.pl

13. J. Jasiczak, Building Technologies II (Poznan University of Technology, Poznań, 2003) [in Polish] 